\title{
Testing the Impact of Organizational Justice on Affective Commitment to Change with Work Engagement as Mediator
}

\author{
Yurnalis $^{1 *}$, Wustari Mangundjaya ${ }^{1}$
}

\author{
${ }^{I}$ Departement of Psychology, Universitas Indonesia, Depok, Indonesia \\ *Corresponding author. Email: Yurnalisnita2008@gmail.com
}

\begin{abstract}
This study aims to examine the effect of four dimensions of organizational justice (distributive justice, procedural justice, interpersonal justice, and informational justice) on affective commitment to change. We also explore the role of work engagement as a mediator in the relationship between organizational justice dimensions and affective commitment to change. We draw on social exchange theory (SET) to explain the relationship. Data were collected from civil servants working in health care facilities at DKI Jakarta Province $(\mathrm{N}=145)$. Results of structural equation modeling (SEM) analysis showed that procedural justice and interpersonal justice have a significant effect on affective commitment to change. However, SEM analysis showed that work engagement did not mediate the relationship between organizational justice dimensions and affective commitment to change.
\end{abstract}

Keywords: organizational justice, affective commitment to change, work engagement

\section{INTRODUCTION}

Change is a must for an organization to survive in overcoming external pressures and demands from within the organization itself. Unfortunately, change does not always go according to the plan set. Various obstacles that must be faced by the organization to make change successful. Research shows that nearly $70 \%$ of changes made by organizations failed [1]. One of several factors causing failure to implement changes in organizations is due to a lack of commitment to change by the members of the organization [2][3][4][5]. Employee's commitment to supporting organizational change has been a concern for scholars and practitioners in recent years. Previous study show commitment to change has an impact on organizational outcomes [6]. The results of previous studies noted several predictors of commitment to change [4], stated predictors that effect commitment to changes originating from individuals and the environment. In this regard perception of organizational justice is one of the predictors that influence commitment to change [7]. When members of the organization feel the rewards, procedures, treatment, and information under employee expectations, then the employee will perceive these feelings as a justice given by the organization [8]. Employees who feel the justice obtained from the organization under expectations will have a positive effect on attitudes and behavior in work [9]. Employees who feel justice will show a positive influence on the organization, among others; attitude and behavior of good cooperation with organizations [10], compliance in carrying out actions related to change [10]
[3], low desire to leave work [11], and improved performance [5]. The previous study stated that high score of organizational justice had a positive effect on work engagement. Employees who feel respected fairly enough by the management will be intrinsically motivated to devote their enthusiasm, energy, and concentration to the work [12]. Furthermore, individuals who have a high score on work engagement are expected have to a high level of commitment to support change initiated by the organization [4].

In this study we assess the influence of organizational justice dimensions on affective commitment to change that has not received much attention in previous research. In addition, we also assess the role of work engagement in mediating the relationship of organizational justice dimensions to affective commitment to change. Organizations may benefit from taking the results of this study in consideration during an organizational change process.

\section{LITERATURE REVIEW}

\subsection{Organizational justice and affective commitment to change}

First, Commitment in general means the power of mindset that binds a person to take actions to achieve a target [13] The understanding of commitment organization by Meyer et al became the basis of the definition of commitment to changes used in this study. Commitment to change is a 
power of mindset that makes a person motivated to take actions that are deemed necessary for the successful implementation of change initiative [14]. Herscovitch \& Meyer suggests that there are three dimensions of commitment to change, namely: affective commitment to change, continuance commitment to change and normative commitment to change.

Affective commitment to change is a mindset that binds a person to actions that reflect the devotion to afford support for change based on beliefs in the prosperity attached to it. Whereas continuance commitment to change is a responsibility to engage in changes based on transactional considerations. In other words, persons committed to supporting change initiative because they consider the losses associated with failure to afford support for change. Finally, normative commitment to change is a commitment to engage in changes that arise from the sense of having moral accountability to succeed in the changes initiated by the organization.

Affective commitment to change is an emotional touch and eagerness to support implementation change initiative base on the consideration that these changes bring benefits to both themselves and the organization [6]. Individuals who have affective commitment to change will develop positive emotions related to change and will be actively bound to make those changes happen. Besides, high-level affective commitment to change has positive energy and emotions which in turn have an impact on positive behaviors in the workplace, including behaviors that support change [6][3]. Bouckenooghe et al stated that high affective commitment individuals have cooperation behavior and championing behavior compared to individuals with a low affective commitment to change. Previous studies stated that there are several factors that influence commitment to changes namely; communication change [15], trust in organizations [16][15], participation in decision making [17] leadersubordinate relationships [5], leadership [18][19], and organizational justice [15][7][20].

Justice is known as a moral act or decision that is considered true based on ethics, religion, or law [21]. Organizational justice describes employee perceptions of fairness given by the organization [22]. There are four dimensions of organizational justice, namely: distributive justice, procedural justice, interpersonal justice, and informational justice [22]. Distributive justice is a perception of justice arising from an assessment of the benefits of the work obtained. Rewards received in the form of salaries, promotions, facilities and others [9]. Procedural justice is a perception of justice against the processes or mechanism in deciding the outcomes for their inputs to the organization [23]. Cropazano et al interpret procedural justice as justice regarding the actions or rules used to regulate outcomes [24]. When individuals feel that decisions about procedures are considered accurate, consistent, unbiased, then individuals will perceive as justice [25]. Interpersonal justice concerns the conditions of treatment received by individuals at the time the application of rules in the workplace. Informational Justice Justice that concerns the quantity and quality of the information received regarding decision-making related to procedures [22]

Organizational justice is a multidimensional construct where each facet of justice is linked to a distinct outcome variable [22]. Scholars have proven that perceive organizational justice have an impact on attitudes and behaviors related to work. The previous study also showed that organizational justice is correlated to high-level job satisfaction [9]. Furthermore, the research study stated that organizational justice has affects workers willing to leave work (turnover intention). In other words, the higher the score of perceived justice, the lower the desire to leave work. Other studies further stated that workers who sense they have been served fairly will show a high commitment to the organization [26]. There are still many positive influences of organizational justice towards attitudes and behavior towards work, among others; increasing innovative behavior (innovative work behavior) [27], improving work performance [28], increasing commitment to change [15].

Several studies have proven the effect of organizational justice on the commitment to the organizational change initiative. Mangundjaya stated that organizational justice has a significant effect on affective commitment to change [15]. This means the higher score perceptions of justice, the higher the commitment to organizational change.[29] examined the relationships between the four dimensions of organizational justice on affective commitment to change, they proved that the four facets of organizational justice (distributive justice, procedural justice, interpersonal justice, and informational justice) have a positive correlation with affective commitment to change. Similar results are shown by Foster [30] who found that the four facets of organizational justice acts as a predictor of affective commitment to change. Based on the arguments described, we formulated the research hypothesis as follows:

Hypothesis 1: Distributive justice has a positive effect on affective commitment to change.

Hypothesis 2: Procedural justice has a positive effect on affective commitment to change.

Hypothesis 3: Interpersonal justice has a positive effect on affective commitment to change.

Hypothesis 4: Informational justice has a positive effect on affective commitment to change.

We propose our research model as follows:

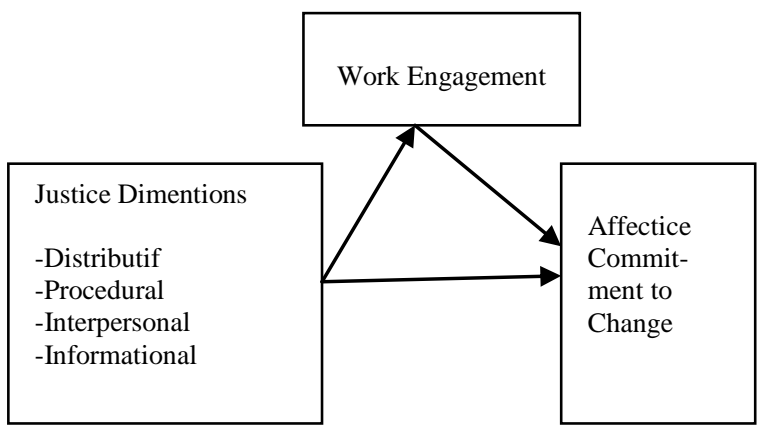

Figure 1 Hypothesized model 


\subsection{Work engagement as a mediator between organizational justice and afektif commitment to change}

We assumed work engagement mediated relationships between the four dimensions of organizational justice and affective commitment to change (Figure 1). The mechanism can be explained through social exchange theory (SET). SET theory states that there is an exchange of returns from employees on actions received from organizations [31]. According to the SET theory, employees who get fair treatment from the organization will return the same treatment to the organization, among others, by displaying a high level of work engagement [32]. The results of previous studies also showed that engaged employees correlate with a commitment to change [4]. However, based on the literature search, we did not find other studies that examined the effect of work engagement with the commitment to change. Therefore, further research is needed to clarify the role of work engagement on affective commitment to change. Based on the above descriptions, we propose our hypothesis, namely:

Hypothesis 6: Work engagement has a role as a mediator between organizational justice dimensions and affective commitment to change.

Hypothesis 7: Work engagement has a role as a mediator between Distributive and affective commitment to change. Hypothesis 8: Work engagement has a role as a mediator between Procedural justice and affective commitment to change.

Hypothesis 9: Work engagement has a role as a mediator between informational justice and affective commitment to change.

\section{METHOD}

\subsection{Participans and Procedures}

Participants were public service employees between 1956 years old who work at public health centers within the health office of DKI Jakarta Province. Of the 200 distributed questionnaires, 145 were returned (response rate $=72.5 \%$ ). Participants consisted of $27 \%$ male and $73 \%$ female. The mean age of participants was 34.39 years $(S D=8.39)$, with an average working period of 7.91 years $(S D=6.58)$. Participants' educational attainment levels varied, with $45.5 \%$ held a diploma degree, $40 \%$ had an undergraduate degree, $13.8 \%$ completed senior high school, $0.7 \%$ held a postgraduate degree.

The respondents participated in the study voluntarily by first filling out the informed consent. We ensured that their participation was voluntary, anonymous, and confidential.

\subsection{Measurement}

\subsubsection{Affective Commitment to Change (AC2C)}

AC2C was measured using affective commitment to change questionnaire from Herscovits and Meyer [14], consisting of six items with modified and translated by [4]. This measure used a Likert scale of 1-6 (1 = Strongly Disagree, $6=$ Strongly Agree) with a Cronbach's Alpha coefficient of 0.83 . An example of the items is," In my opinion, the situation will be better without any changes in the organization". A high score indicates a high level of affective commitment to change".

\subsubsection{Work Engagement.}

Work engagement was measured using the Utrecht Work Engagement Scale (UWES)-9 [12]. UWES-9 consisted of 9 items using a Likert-type scale ranging from 1-6 $(1=$ Never, $6=$ Always) with a Cronbach's Alpha coefficient of 0.92. A sample item is, "I feel strong and energized at work". A high score indicates a high level of work engagement. The questionnaire was translated into Indonesian language and modified.

\subsubsection{Organizational Justice}

Measurement of organizational justice variables uses a measuring instrument made by Colquitt [22] consisting of 20 items with a Likert-type scale ranging from 1-6 (1 $=$ Strongly Disagree, $7=$ Strongly Agree) and a Cronbach's Alpha coefficient of 0.95. The questionnaire consists of four dimensions of organizational justice (distributive justice, procedural justice, interpersonal justice, and informational justice). As an example, one of the items states, "Organizations apply regulations consistently". A high score indicates a high perception of organizational justice. The questionnaire was translated into Indonesian language and modified.

\subsection{Data Analysis}

Before testing the hypothesis, we conducted a confirmatory factor analysis on LISREL 8.80 to test the discriminant validity and reliability of the measures. The hypothesis was tested using structural equation modeling (SEM) analysis on LISREL 8.80. 


\section{RESULTS AND DISCUSSION}

\subsection{Confirmatory Factor Analysis (CFA)}

The CFA results were reported in Table 1.

Table 1 Results of the Confirmatory Factor Analysis (N=216)

\begin{tabular}{|l|l|c|c|c|c|c|c|c|c|}
\hline \multicolumn{1}{|c|}{ Model } & \multicolumn{1}{|c|}{$\begin{array}{c}\text { Latent } \\
\text { variables }\end{array}$} & $\boldsymbol{d} \boldsymbol{f}$ & $\boldsymbol{\chi}^{2}$ & $\boldsymbol{X}^{2} / \boldsymbol{d f}$ & $\mathbf{C F I}$ & GFI & NFI & RMSEA & SRMR \\
\hline $\begin{array}{l}\text { Hyphotesiz } \\
\text { ed model }\end{array}$ & $\begin{array}{l}\text { WE, DJ, PJ, } \\
\text { IPJ, IMJ, } \\
\text { AC2C }\end{array}$ & 579 & 1114.49 & 1.93 & 0.95 & 0.70 & 0.91 & 0.07 & 0.083 \\
\hline $\begin{array}{l}\text { One factor } \\
\text { model }\end{array}$ & General factor & 594 & 2805.11 & 4.72 & 0.84 & 0.36 & 0.80 & 0.22 & 0.15 \\
\hline $\begin{array}{l}\text { Three } \\
\text { factor } \\
\text { model }\end{array}$ & OJ,WE, AC2C & 619 & 1316.01 & 2.12 & 0.95 & 0.85 & 0.91 & 0.08 & 0.09 \\
\hline $\begin{array}{l}\text { Five factor } \\
\text { model }\end{array}$ & $\begin{array}{l}\text { AC2C,OJ, } \\
\text { Vigor, } \\
\text { Dedication, } \\
\text { Absorption }\end{array}$ & 584 & 1904.08 & 3.26 & 0.92 & 0.58 & 0.88 & 0.125 & 0.11 \\
\hline $\begin{array}{l}\text { Eight } \\
\text { factor } \\
\text { model }\end{array}$ & $\begin{array}{l}\text { AC2C, } \\
\text { DJ,PJ,IPJ,IMJ, } \\
\text { Vigor, } \\
\text { dedication, } \\
\text { absorption }\end{array}$ & 566 & 1178.29 & 2.08 & 0.95 & 0.71 & 0.92 & 0.08 & 0.078 \\
\hline
\end{tabular}

We compared the proposed six-factor model (Distributive justice, procedural justice, interpersonal justice, informational justice, and work engagement) with four theoretically appropriate alternative models, namely 1) a one-factor model in which all indicators were allowed to load into a latent variable, 2) a three-factor model in organizational justice, work engagement, and affective commitment to change acted as latent variables, 3) a fivefactor model, where organizational justice, affective commitment to change, and the three dimensions of work engagement (vigor, dedication, and absorption) served as latent variables, and 4) an eight-factor model in which four-dimensional organizational justice, three-dimensional work engagement, and affective commitment to change were considered as latent variables. The Goodness-of-fit index is recommended by [33] and [34] consist of root mean square error of approximation (RMSEA), standard root mean square residual (SRMR), comparative fit index (CFI), and goodness of fit (GFI) index. RMSEA must be equal to or less than 0.08 , and CFI should be greater than 0.90 . Hair et al suggested that GFI should be greater than 0.90, whereas SRMR below 0.08 indicates conformity [33]. The CFA reveals that the six-factor model (The four facet of justice, work engagement and, affective commitment to change) had a better level of fit than the other four alternative models.

This indicates that the six variables had acceptable discriminant validity. We then calculated The average variance of extract (AVE) for Distributive justice, procedural justice, informational justice, interpersonal justice, work engagement and, affective commitment to change, the value of each is $0.67,0.55,0.65,0.73,0.57$ and 0.57, respectively. Because all variables have AVE above 0.5 , thus all instrument is reliable. We also calculate Chronbach' Alpha of all variables (Table 2). All variables were reliable as the Chronbach's Alpha of each variable passes 0.60. Table 2 shows the means, standard deviations, Cronbach alphas and correlations among research variables. Level of education has a significant negative correlation on procedural justice $(r=-0.27, p>0.05)$. This means that the higher the level of education, the lower the perception of procedural justice. Age has a positive correlation on procedural justice $(r=0.17, p<0.05)$. This means that the higher the age, the higher the perception of procedural justice. While gender and tenure do not correlate with affective commitment to change, work engagement, and organizational justice dimensions. Procedural justice, interpersonal justice, informational justice and work engagement have a significant correlation on affective commitment to change $(r=0.34, p$ $<0.01 ; \mathrm{r}=0.32, \mathrm{p}<0.01 ; \mathrm{r}=0.30, \mathrm{p}<0.01 ; \mathrm{r}=0.294, \mathrm{p}<0.01$, respectively). However, distributive justice does not correlate with affective commitment to change $(r=0.05, \mathrm{p}$ $>0.05$ ). Furthermore, we also correlate the facet of justice on work engagement, noted that distributive justice has a positive correlation on work engagement $(r=0.25, \mathrm{p}$ $<0.01$ ), that means higher score distributive justice, higher-level work engagement. Procedural justice has a positive correlation on work engagement $(\mathrm{r}=0.51$, $\mathrm{p}<0.01$ ), that means the higher perception of procedural justice, higher-level work engagement. Next, interpersonal justice has a positive correlation on work engagement $(\mathrm{r}=0.43, \mathrm{p}<0.01)$, that means higher score interpersonal justice, higher-level work engagement. Finally, 
informational justice has a significant positive correlation on work engagement $(r=0.48, p<0.01)$, that means higher score informational justice, higher-level work engagement.

\subsection{Testing the Hypotheses}

The results of the structural model analysis obtained a model fit with data $(\chi 2=986.59$, df $=608 ; \chi 2 / \mathrm{df}=$ 1.62; CFI $=0.97$; PNFI $=0.85 ;$ RMSEA $=0.06 ;$ SRMR $=0.082$ ). The results of the full estimation of latent variable models are shown in Figure 2. From the model, it was known that distributive justice (DJ) had no significant effect on affective commitment to change $(\gamma$ $=-0.03, \mathrm{t}=-0.26$ ). Thus hypothesis 1 was not supported by data. The next result showed that the procedural justice $(\mathrm{PJ})$ had a positive effect on affective commitment to change $(\gamma=0.61, t=2.72)$, This means that the higher perception of procedural justice, the higher willingness to support organizational change agenda.

Table 2 Summary of Statistic and Correlations Among Variables

\begin{tabular}{|l|c|c|c|c|c|c|c|c|c|c|c|c|c|}
\hline \multicolumn{2}{|c|}{ Variables } & Mean & $\boldsymbol{S D}^{\mathbf{c}}$ & $\mathbf{1}$ & $\mathbf{2}$ & $\mathbf{3}$ & $\mathbf{4}$ & $\mathbf{5}$ & $\mathbf{6}$ & $\mathbf{7}$ & $\mathbf{8}$ & $\mathbf{9}$ & $\mathbf{1 0}$ \\
\hline 1 & Age & 34.39 & 8.39 & - & & & & & & & & & \\
\hline 2 & Education & 2.86 & 0.34 & -0.155 & - & & & & & & & & \\
\hline 3 & Gender & 1.73 & 0.44 & -0.143 & $0.389^{\mathrm{a}}$ & - & & & & & & & \\
\hline 4 & Tenure & 7.91 & 6.58 & $0.529^{\mathrm{a}}$ & -0.072 & $-0.168^{\mathrm{b}}$ & - & & & & & & \\
\hline 5 & AC2C & 4.66 & 0.73 & 0.038 & -0.100 & -0.095 & 0.080 & $(0.74)$ & & & & & \\
\hline 6 & DJ & 4.44 & 0.95 & 0.041 & -0.135 & 0.021 & 0.030 & 0.057 & $(0.88)$ & & & & \\
\hline 7 & PJ & 4.48 & 0.84 & $0.169^{\mathrm{b}}$ & $-0.216^{\mathrm{a}}$ & -0.141 & 0.134 & $0.341^{\mathrm{a}}$ & $0.458^{\mathrm{a}}$ & $(0.89)$ & & & \\
\hline 8 & IPJ & 4.47 & 0.82 & -0.016 & -0.076 & -0.062 & 0.063 & $0.318^{\mathrm{b}}$ & $0.424^{\mathrm{a}}$ & $0.522^{\mathrm{a}}$ & $(0.91)$ & & \\
\hline 9 & IMJ & 4.45 & 0.87 & 0.028 & -0.114 & -0.069 & 0.058 & $0.302^{\mathrm{a}}$ & $0.322^{\mathrm{a}}$ & $0.682^{\mathrm{a}}$ & $0.770^{\mathrm{a}}$ & $(0.91)$ & \\
\hline 10 & WE & 4.46 & 0.87 & -0.006 & -0.061 & -0.060 & 0.014 & $0.294^{\mathrm{b}}$ & $0.249^{\mathrm{a}}$ & $0.515^{\mathrm{a}}$ & $0.434^{\mathrm{a}}$ & $0.479^{\mathrm{a}}$ & $(0.95)$ \\
\hline
\end{tabular}

${ }^{\mathrm{a}}$ Significant at $\mathrm{p}<0.01,{ }^{\mathrm{b}}$ Significant at $\mathrm{p}<0.05,{ }^{\mathrm{c}} \mathrm{SD}=$ Standar Deviation

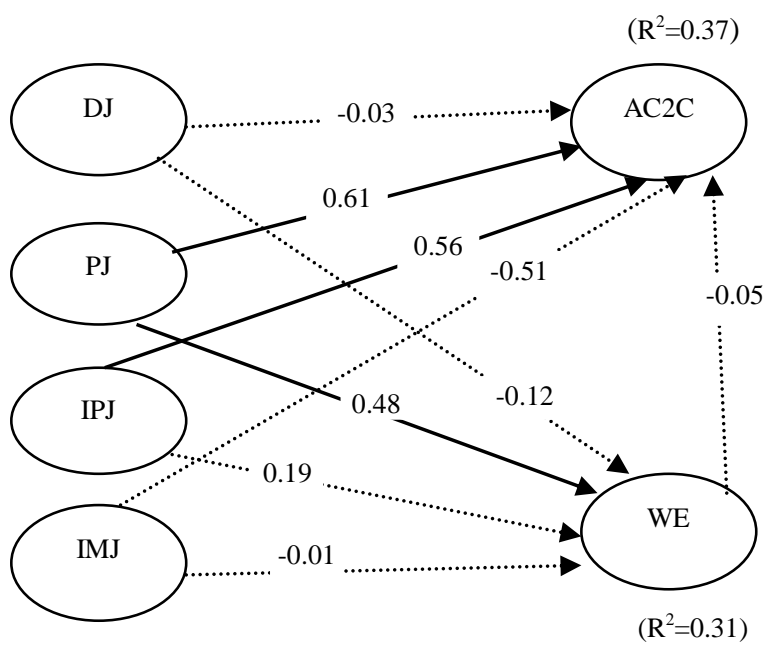

Figure 2 Final structural model

Thus hypothesis 2 was supported by data The analysis showed that hypothesis 3 was confirmed because interpersonal justice had a significant effect on affective commitment to change $(\gamma=0.56, \mathrm{t}=2.25)$. Finally, the analysis showed informational justice has no significant effect on affective commitment to change $(\gamma=-0.51, \mathrm{t}=1.56)$. Thus hypothesis 4 was not supported by data.

The outcomes of the structural analysis showed the total effect of Distributive justice on a commitment to change was not significant (total effect $=-0.04, \mathrm{t}=$ 0.31). Distributive justice had no a significant indirect effects through work engagement (indirect effect $=$ $0.01, \mathrm{t}=-0.48)$. This result showed that work engagement had no significant mediating role that strengthens the effect of distributive justice on affective commitment to change so that the hypothesis 5 was not supported. The results of the analysis also showed that work engagement had no a mediating role on the relationship between procedural justice (indirect effect $=0.03, \mathrm{t}=0.51$ ), interpersonal justice (indirect effect $=$ $0.01, \mathrm{t}=0.47)$ and informational justice indirect effect $=0.00, \quad \mathrm{t}=-0.04)$ on affective commitment to change.

\subsection{Discussion}

The results of the structural analysis showed that procedural justice and interpersonal justice had signifikans effect on affective commitment to change. However, distributive justice and informational justice had no significant effect on affective commitment to change. This means that to increase affective commitment for the organizational change it is necessary to pay attention to the clarity of the change procedures that will be carried out. To improve the perceptions of organizational procedural justice, ensure that the process is carried out is consistent, accurate, 
unbiased, represents the voice of employees, does not violate ethics and morals, and considers the opinions of employees [35]. Besides, the criteria for procedural justice include two things namely; process control and decision control [26]. Process control is the capability to voice views or arguments against procedures in determining outcomes. While the decision control is the capability to control the outcomes of itself. Furthermore, to increase employee's affective commitment to organizational change, it is important to give attention to interpersonal justice. Previous research also stated that perceive interpersonal justice have a positive impact on the commitment to change [30][4][29]. The perception of interpersonal justice can be improved through; respectful treatments, accurate explanations, openness and truthfulness, restraint and being careful of propriety [26].

The results also showed that work engagement had no role as a mediator. In this research, we used the work engagement construct according to Schaufeli framework [36]. There are three dimensions of work engagement namely; vigor, dedication, and absorption [36]. Vigor is defined as energy and perseverance to do the job. Dedication is defined as enthusiasm and pride in doing the job, and absorption is defined as the state of being preoccupied and having full concentration on the job. It should be suspected that being enthusiastic and focusing on work today will be difficult to commit to change. Further study is needed to investigate the role of each dimension of work engagement on the commitment to change. This result can also be a lesson for organizations that are running the change agenda to think about spending energy and resources to stimulate work engagement on their employees.

Organizations may benefit from taking the results of this study in consideration during an organizational change process. We propose companies to consider procedural justice and interpersonal justice to boost the score of employee's commitment to change. The leader in the organization should explain the change procedures consistently, accurate, free of bias, correctly and propriety. Organizational should treat their employees respectively, dignity and truthfulness to increase their perception of interpersonal justice.

This research has several limitations that need to be discussed. First, this study was conducted only in one public service organizations which can not be generalized for all types of organization. In future studies, we suggest replicating the study using other populations, such as private organizations and other types of organization. Second, this research used a cross-sectional design that prevented us from confirming the causal relationship between our research variables. Longitudinal research would need to be done in the future to determine whether a causal relationship between the study variables exists. Third, data were obtained using the only self-report method, therefore raising the probability of common method bias [37]. In addition to that, the self-report method has the potential of being influenced by a social desirability bias. We suggest future researchers employ temporal separation in collecting the predictor, mediator, and outcome variables, or to use diary study to consider the fluctuations of the levels of the variables over time [37].

\section{CONCLUSIONS}

This research found that procedural justice and interpersonal justice as two important variables for predicting affective commitment to change. Structural equation modeling analysis showed work engagement does not serve as an underlying psychological process that helps explain the relationship between organizational justice dimensions and affective commitment to change. As there is still a lack of research on the relationship between organizational justice dimensions and affective commitment to change, we suggest there will be more extensive research in this area to further examine the possible mediating and moderating roles of variables.

\section{REFERENCES}

[1] A. Sologar, B. Ewenstein, and W. Smith, "Changing change management," McKinsey Digit., 2015 .

[2] T. Cummings and C. Worley, Organization development \& change, Tenth. Stamford,USA: Cengage Learning, 2015.

[3] P. Neves and A. Caetano, "Commitment to change: Contributions to trust in the supervisor and work outcomes," Gr. Organ. Manag., vol. 34, no. 6, pp. 623-644, 2009.

[4] W. L. H. Mangundjaya, "The Role of Employee Engagement on the Commitment to Change (During Large-Scale Organizational Change in Indonesia)," Int. J. ofMultidisciplinary Thought, vol. 4, no. 1, pp. 375-383, 2015.

[5] J. T. Parish and S. Cadwallader, "Want to, need to, ought to: Employee commitment to organizational change," J. Organ. Chang. Manag., vol. 21, no. 1, pp. 32-52, 2008.

[6] D. Bouckenooghe, G. M. Schwarz, and A. Minbashian, "Herscovitch and Meyer's ThreeComponent model of commitment to change: Meta-analytic findings," Eur. J. Work Organ. Psychol., vol. 24, no. 4, pp. 578-595, 2015. 
[7] A. Paolillo, S. Platania, P. Magnano, and T. Ramaci, "Organizational justice, optimism and commitment to change," Procedia - Soc. Behav. Sci., vol. 191, pp. 1697-1701, 2015.

[8] D. Bouckenooghe, D. De Clercq, and J. Deprez, "Interpersonal Justice, Relational Conflict, and Commitment to Change: The Moderating Role of Social Interaction," Appl. Psychol., vol. 63, no. 3, pp. 509-540, 2014.

[9] X. Pan, M. Chen, Z. Hao, and W. Bi, "The effects of organizational justice on positive organizational behavior: Evidence from a large-sample survey and a situational experiment," Front. Psychol., vol. 8, pp. 1-16, 2018.

[10] J. P. Meyer, E. S. Srinivas, J. B. Lal, and L. Topolnytsky, "Employee commitment and support for an organizational change: Test of the threecomponent model in two cultures," J. Occup. Organ. Psychol., vol. 80, no. 2, pp. 185-211, 2007.

[11] G. B. Cunningham, "The relationships among commitment to change, coping with change, and turnover intentions," Eur. J. Work Organ. Psychol., vol. 15, no. 1, pp. 29-45, 2006.

[12] W. Schaufeli and A. Bakker, "Utrecht Work Engagement Scale," Occup. Heal. Psychol. Unit Utr. Univ., 2004.

[13] J. P. Meyer, D. J. Stanley, L. Herscovitch, and L. Topolnytsky, "Affective, continuance, and normative commitment to the organization: A meta-analysis of antecedents, correlates, and consequences," J. Vocat. Behav., vol. 61, no. 1, pp. 20-52, 2002.

[14] L. Herscovitch and J. P. Meyer, "Commitment to organizational change: Extension of a threecomponent model," J. Appl. Psychol., vol. 87, no. 3, pp. 474-487, 2002.

[15] W. L. Mangundjaya, "The Role of Communication , Trust and Justice in Commitment to Change," Proc. Int. Conf. Bus. Manag. Corp. Soc. Responsib. (ICBMCSR 14), Febr. 14-15, 2014, Batam, Indones., pp. 74-77, 2014.

[16] H. J. Kalyal and S. K. Saha, "Factors affecting commitment to organizational change in a public sector organization," NUST Journal of Business and Economics, vol. 1, no. 1. pp. 1-10, 2008.

[17] A. Chawla and K. Kelloway, "Predicting openness and commitment to change," Leadersh. Organ. Dev. J., vol. 25, no. 6, pp. 485-498, 2004.

[18] D. M. Herold, D. B. Fedor, S. Caldwell, and Y. Liu, "The effects of transformational and change leadership on employees' commitment to a change: A multilevel study," J. Appl. Psychol., vol. 93, no. 2, pp. 346-357, 2008.

[19] Y. Liu, "When change leadership impacts commitment to change and when it doesn't a multi-level multi-dimensional investigation," Georg. Inst. Technol., vol. 22, no. 2, pp. 178-189, 2010.

[20] A. Stjernen, "Perceived fairness and resistance to organizational change in relation to changecommitment," Univ. Osloensis, 2009.

[21] V. Pekurinen, “Organizational justice and collaboration between nurses as correlates of violent assaults by patients in psychiatric care," Univ. Turku, Finl., 2017.

[22] J. A. Colquitt, "On the dimensionality of organizational justice: A construct validation of a measure," J. Appl. Psychol., vol. 86, no. 3, pp. 386-400, 2001.

[23] A. Suliman and M. Al Kathairi, "Organizational justice, commitment and performance in developing countries: The case of the UAE," Empl. Relations, vol. 35, no. 1, pp. 98-115, 2013.

[24] R. Cropanzano, D. E. Bowen, and S. W. Gilliland, "The management of organizational justice.," Acad. Manag. Perspect., vol. 21, no. 4, pp. 34-48, 2007.

[25] J. A. Colquitt, B. A. Scott, T. A. Judge, and J. C. Shaw, "Justice and personality: Using integrative theories to derive moderators of justice effects," Organ. Behav. Hum. Decis. Process., vol. 100, no. 1, pp. 110-127, 2006.

[26] J. A. Colquitt, M. J. Wesson, C. O. L. H. Porter, D. E. Conlon, and K. Y. Ng, "Justice at the millennium: A meta-analytic review of 25 years of organizational justice research," J. Appl. Psychol., vol. 86, no. 3, pp. 425-445, 2001.

[27] T. Akram, M. J. Haider, and Y. X. Feng, "The effects of organizational justice on the innovative work behavior of employees: An empirical study from china," Autre, vol. 2, no. January, pp. 114126, 2016 
[28] A. Swalhi, S. Zgoulli, and M. Hofaidhllaoui, "The influence of organizational justice on job performance: the mediating effect of affec- tive commitment," J. Manag. Dev., vol. 36, no. 4, 2017.

[29] J. Shin, M. G. Seo, D. L. Shapiro, and M. S. Taylor, “Maintaining Employees' Commitment to Organizational Change: The Role of Leaders' Informational Justice and Transformational Leadership," J. Appl. Behav. Sci., vol. 51, no. 4, pp. 501-528, 2015.

[30] R. D. Foster, "Resistance, Justice, and Commitment to Change," Hum. Resour. Dev. Q., vol. 21, no. 1, pp. 1-38, 2010.

[31] R. Cropanzano and M. S. Mitchell, "Social Exchange Theory: An Interdisciplinary Review," J. Manage., no. April, 2014.

[32] X. Lyu, "Effect of organizational justice on work engagement with psychological safety as a mediator: Evidence from china," Soc. Behav. Pers., vol. 44, no. 8, pp. 1359-1370, 2016.

[33] B. M. Byrne, "Structural Equation Modeling With AMOS, EQS, and LISREL: Comparative Approaches to Testing for the Factorial Validity of a Measuring Instrument AMOS, EQS, and LISREL : Comparative Approaches to Testing for the Factorial Validity of a Measuring Instru," Int. J. Test. I, vol. 5058, no. 1, pp. 55-86, 2001.

[34] L. Hu, P. M. Bentler, and L. Hu, "Cutoff criteria for fit indexes in covariance structure analysis: Conventional criteria versus new alternatives Cutoff Criteria for Fit Indexes in Covariance Structure Analysis: Conventional Criteria Versus New Alternatives," Struct. Equ. Model. A Multidiscip. J., vol. 5511, pp. 1-55, 1999.

[35] C. P. Zapata-Phelan, J. A. Colquitt, B. A. Scott, and B. Livingston, "Procedural justice, interactional justice, and task performance: The mediating role of intrinsic motivation," Organ. Behav. Hum. Decis. Process., vol. 108, no. 1, pp. 93-105, 2009.

[36] W. B. Schaufeli, M. Salanova, V. G. Roma, and A. . Bakker, "The measurement of engagement and burnout: a two sample of confirmatory factor analytic approach.," J. Happiness Stud., vol. 3, pp. 71-92, 2002.

[37] P. M. Podsakoff, S. B. MacKenzie, J. Y. Lee, and
N. P. Podsakoff, "Common Method Biases in Behavioral Research: A Critical Review of the Literature and Recommended Remedies," J. Appl. Psychol., vol. 88, no. 5, pp. 879-903, 2003. 